\title{
On the development and developing trend of the electric automation embedded systems
}

\author{
YUE Xiangyu \\ School of Management and Engineering, Nanjing University; Nanjing Jiangsu; 210008; PR China
}

Email address:

yuexiangyu168@gmail.com

\section{To cite this article:}

YUE Xiangyu. On the Development and Developing Trend of the Electric Automation Embedded Systems. American Journal of Embedded Systems and Applications. Vol. 1, No. 1, 2013, pp. 17-22. doi: 10.11648/j.ajesa.20130101.13

\begin{abstract}
The electrical automation embedded control system is such an automatic control system in which one or several independent full-featured small or micro computer devices as a component or subsystems are combined with control system organically to construct a more powerful and more sophisticated automatic control system. From perspectives of the processing power and the characteristics of handling signals, the commonly used embedded processors include such four types as single-chip microcontrollers, digital signal processors, embedded microprocessors, on-chip systems. There are a lot of common embedded real-time operating systems. The performance, functionality, cost and applications of WinCE, Linux and eCos have been analyzed and compared. It has great reference and guidance significance for people to develop and apply the embedded systems. The automation embedded systems will develop in network, rapid, market-oriented, concise, scientific, environmental direction.
\end{abstract}

Keywords: Automation, Embedded Systems, Real-Time Operating System, Microprocessor, Developing Trends

\section{Introduction}

Since the second industrial revolution, electronic technology has been developing rapidly, the scale of integrated circuits becoming larger and larger, the level of its integration higher and higher, the processing speed of chip faster and faster. A vigorous new revolution is undergoing in the modern electrical automation control field. ${ }^{[1]}$ However, the greatest "hero", who makes electrical automation control system have a high-speed processing and high reusability features, should be the strong development and extensive application of embedded systems technology. The so-called embedded systems technology is to combine one or several independent full-featured small or microcomputer devices as a component or subsystem with control system organically into a more powerful, more sophisticated automatic control system. $^{[2]}$

The embedded system of electrical automation control system includes: embedded hardware, embedded software, embedded operating system, etc. ${ }^{[3]}$ The embedded hardware is the base and prerequisite to construct embedded application system. The embedded real-time operating system is the software platform on which embedded application system runs. The application of embedded software is to achieve the corresponding automatic control functions of the system. In recent years, embedded hardware and embedded real-time operating system have been developing rapidly with the development of computer technology and with each passing day. Comprehensively and accurately understanding and grasping the development and research status of embedded system is particularly important to electrical automation control system development. The author, in the text, analyzes and studies the current popular embedded hardware and real-time operating system detailedly, especially achieving a more detailed analysis and comparison to the performance, functionality, cost, resource and application prospects of the three typical embedded real-time operating system. This has important practical significance and value to the embedded system development.

\section{Embedded Hardware}

In the embedded system of electric automatization, the hardware of embedded processor is a basic factor to apply and develop the embedded system. From its handling capacity and the features of signal processing, it mainly includes the following several forms, which is single chip, digital signal processor, microprocessor unit, system-on-a-chip, etc. 


\subsection{Single Chip (MCU)}

Single chip is to integrate CPU, RAM, ROM, A variety of $\mathrm{I} / \mathrm{O}$ mouth and interrupt system, timer (having data processing functions), and VFD, PWM, analog multiplexer, $\mathrm{A} / \mathrm{D}$ converter on a silicon wafer in high density to perfect the computer system, which is generally called MCU. It has the advantages of small volume, light quality, and cheap price for application and development. At present, there exists many commonly used MCUs, such as INTEL, ATMEL (51MCU), TI (51MCU), PIC, STC, EMC, PHLIPIS 51LPC (51MCU), HOLTEK, SONIX and so on. Although these MCUs have a certain arithmetic capability, they lack superiority when operating multiple data. Therefore, it only could be used in the control system of small industry, intelligent instrumentation, household appliance, communication, and high-grade electronic toy.

\subsection{Digital Signal Processor (DSP)}

Digital signal processor (DSP) refers to a dedicated chip for digital signal processing, which has a strong ability of data processing. Compared to MCU, DSP has a better ability to operate data, and deal with some work like signal collection, transform, filtering, appraisement, strengthen, compression and identification, obtaining the signal pattern that people need. DSP has four development trends. Firstly, its application is being more and more extensive in the audio or video processing of mobile phone and portable audio player, communication and information system, signal and information processing, and automatic control, as well as a variety of fields, including radar, military, aviation, medical treatment, and household appliance. Moreover, it will integrate a wider range of functions, like $\mathrm{A} / \mathrm{D}$ converter, and LCD controller, to greatly reduce the system cost, and the number of devices. Secondly, DSP has been sold as IP, such as the CAMEL, and TRICORE, developed by Yiheng Technology Company. As EDA tool becoming mature, DSP core has being easier to be modified, and be added into a user-specified periphery circuit to achieve a more professional and lower-cost solution of DSP. Thirdly, there exists a wide variety of DSPs. Except for some well-known companies like Texas Instruments, Lucent Technologies, Analog Devies, and Motorola; there are still more than 80 companies that produce DSP. Generally speaking, DSP has two types-- fixed-point DSP, and floating-point DSP. Fixed-point DSP has the most varieties, which develops rapidly, with a processing speed of 20 to 2000 MIPS. As for floating-point DSP, it has mainly been monopolized by TI and $\mathrm{AD}$, with a processing speed of 40 to 1000 mflops. Lastly, the performance of DSP has three degrees, which are low, medium, and high. The structure of high-end DSPs has experienced profound changes, showing a diversified trend.

\subsection{Micro Processor Unit (MPU)}

Microprocessor unit, also known as MPU, is evolved from the CPU of general-purpose computer. It has the processor that is higher than 32-pins, with high performance and high price. It is different from the processor of computer, however, in practical embedded application, it only retains the functioning hardware, related closely with embedded application. And all the redundant functions have been deleted. Therefore, MPU could meet the special need of embedded application with lowest consumption and resource. The MPU is superior to any other general controlling computer in size, weight, cost, reliability and so on. On The Present Situation, the types of MPU mainly are AM186/88, SC-400, 386EX, 68000, POWER PC, MIPS, ARM/STRONGARM Series, etc. ARM/STRONGARM is specially developed for handheld device, which is moderately-priced. Embedded MPU generally has applied in the following four fields. One is the field of embedded industrial control, such as automobile, electronic equipment, safeguard, mass memory, modem, printer, etc. One is the products of digital consumption, like digital audio player, digital STB, PlayStation, digital camera, digital television, Beidou navigation system, GPS, STB, etc. The other is the field of Communication and network application system, including embedded terminal, ADSL chip, voice/video processing, etc. Also, it is applied in the field of wireless communication and portable products, like laptop, mobile phone, PDA, etc.

\subsection{System-On-a-Chip (SOC)}

System-On-a-Chip means to integrate a complete system in a single chip, packing and grouping some parts or all the necessary circuits. Generally, it is used in the small, and increasingly complicated electronic equipment of clients. For instance, the on-chip system of voice checkout equipment uses this single chip, providing users audio receiving terminal, $\mathrm{ADC}$, microprocessor, storage, input/output logic controller and so on. Apart from only a few devices that could not be integrated, most parts of the embedded system could be integrated into one or several chips, which can greatly help enhance the reliability of the system.

\section{Embedded Operation System (EOS)}

In the development and application of embedded system, hardware refers to support and body, while software means soul and spirit. And embedded operation system is responsible for distributing all the embedded hardware and software, scheduling task, and coordinating concurrent activity, as well as achieving the functions that system need by loading and unloading some modules. Therefore, it holds a significant position in the development and application of embedded system. There are a variety of embedded operation systems. ECos, Linux, WinCE, PalmOS, uClinux, uC/OS-II, Symbian, Psos, VxWorks, ThreadX, NucleusPLUS, Rtems, C Executive, QNX, OSE, and INTEGRITY are some relatively popular types at home and aboard. Most of these embedded operating systems are commercial products, which differ in openness, practicality 
and performance. What's more, their prices are also different, for example, eCos and uClinux are free. In the following text, I would compare two commercial developed RTOS-- WinCE and Linux with the free RTOS-eCos to analyze and compare their performance, function, cost and resource, sharing with our colleagues, who are developing and applying the embedded system.

\subsection{WinCE}

WinCE is the abbreviation of Windows CE, the latest member of the windows family, which is specially designed for HPCs. WinCE is aimed at general purpose operating systems for small equipment, having a typical diskless system with limited memory. It could design a code between the kernel and hardware to set a hardware platform. Also, it allows the complete portable technology to collaborate with the existing Windows desktop technology. Besides, WinCE has the following features, namely, modularization, structuration, application program interface based on win32, and the independence of the processor. WinCE not only has inherited the traditional Windows graphic interface, but also could use the programming tools of Windows 95/98on WinCE platform, such as Visual Basic, Visual $\mathrm{c}++$, etc. In addition, same function and same interface style of Windows 95/98on also could be used on WinCE. In most application software, only if make a simple modification and transplanting, they could be used on WinCE. All in all, this real time operating system, WinCE has been relatively mature. ${ }^{[4]}$ It has abundant of developing information, related with automatic control system, and referable cases, which is convenient for the rapid development and product design.

\subsection{Linux}

Linux is a UNIX-like operating system, written in C programming language and assembly language, conforming to the POSIX standard. This operating system was developed by a Finland hacker, Linus B. Torvalds, which is his try to provide free unix-like operating system, based on the Intel X86. Linux is a core, which refers to two parts of basic thoughts. One is everything is a file; the other one is every software has its certain usage. The core, referred here, is a system software that provide the functions of hardware abstract layer, disk and file system controlling, and multitask. This core is not a set of complete operating system. A complete operating system, based on Linux, is called Linux operating system or GNU/Linux. A typical issued Linux includes Linux core, some GNU libraries and tools, command-line shell, the $\mathrm{X}$ window system with graphical interface and its corresponding desktop environment, like KDE or GNOME. Also, it includes thousands of application software, such as office package, text editor, compiler, scientific instruments and so on. The mainstream distributions of Linux mainly are GNU/Linux, Fedora, Debian, Ubuntu, PCLinuxOS, Gentoo, MandrivaLinux, ArchLinux, Puppylinux, Slackware, Linux, openSUSE, Red, Hat, Mint, CentOS etc.
Linux has the following advantages. Firstly, it could run on a variety of hardware platforms, like SPARC, ALPHA, $\mathrm{X} 86$, and $680 \mathrm{x} 0$. All of them may run on Linux. Of course, Linux is embedded real-time operating system, widely applied in palmtop, STB, and playstation. Secondly, Linux could support multi-processors. When several processors working at the same time, the performance of the system could be greatly enhanced. Thirdly, the cost of Linux is low. And it could be set so that it is extensively used in embedded system, like STB, mobile phone, and mobile device. It is worth noting that for mobile phone, Linux has become the main rival of Symbian OS; for mobile device, Linux becomes the first target of WinCE and Palm OS. ${ }^{[4]}$ Even Tivo digital camera, which is popular at present, uses the customized Linux. Besides, many hardware network firewall and router, like LinkSys, also use Linux to drive. Meanwhile, it utilizes the function of firewall and router, providing by operating systems.

\section{3. eCos}

The full name of eCos is embedded configurable operating system, which is a small open source real-time operating system, launched by Redhat. The difference of eCos and Linux is that eCos makes the operating system into a staticlibrary form to let the application produce another application that has the characteristics of operating system by linker. In all, eCos have the features of Configurable, scalable, portable, and real-time. The main technical feature is its powerful configuration system. Because all of its code is written by $\mathrm{C}++$, and it achieves the configuration and cutting of the system on the source code. From configuration and cutting, there is a huge difference between eCos and Linux. ECos provides an API that is compatible with Linux, allowing us to easily port the Linux application, and the application does not need to run in the complex kernel mechanism of Linux and RAM. The configuration method of eCos is clearer and more convenient, the system level is more explicit and clear than Linux, and transplanting and increasing the drive module is also much easier and more convenient. Generally speaking, to normally operate the Linux, it needs at least $2 \mathrm{MB}$ memory space of RAM, and it does not contain the requirement of applications and service program. When the memory does not support the operation of the embedded Linux, the eCos could replace it, since eCos is developed for RAM memory resource, which has the device with only dozens or hundreds of KB. Also, it is developed for timely operation. Since these characteristics of eCos, more and more people pay attention to it, which is attracting more and more manufacturers to develop their new embedded product with eCos. Lingyang SPCE3200 processor is just a example in cases. Thanks to its special features, eCos could run on a variety of hardware platforms, like ARM, CalmRISC, SUNPLUS, IA-32, SPCE, FR-V, MIPS, Hitachi H8, Motorola 68000, PowerPC, Matsushita AM3x, Nios II, SuperH, SPARC, NEC V8xx,etc. 


\subsection{The Comparison of Three Commonly Used Operating Systems}

\subsubsection{The Comparison of System Resources and Cost}

First of all, we make a detailed statistics and contrast of three embedded operating systems — enCE, Linux, and eCos, in the aspects of available resources, the support of development tools, the price of platform building, and the price of commercial copyright, as shown in Ttable $1-$ The list of system resources and cost:

Table 1. The List of system Resources and Cost

\begin{tabular}{|c|c|c|c|}
\hline System Name & WinCE & Linux & eCos \\
\hline Available Resources & $\begin{array}{l}\text { Microsoft provides various software } \\
\text { components so that they can focus on } \\
\text { the application part for } \\
\text { developing the } \\
\text { product characteristics. }\end{array}$ & $\begin{array}{l}\text { It has a good network support, and is available } \\
\text { for mounting commercial GUI or writing and } \\
\text { establishing GUI by QT. Most of the } \\
\text { application should be written by themselves. }\end{array}$ & $\begin{array}{l}\text { It has a complete network } \\
\text { support. Presently, there is no } \\
\text { GUI, but it could mount other } \\
\text { GUI libraries. Most of the } \\
\text { application should be written } \\
\text { by themselves. }\end{array}$ \\
\hline $\begin{array}{l}\text { The Support of } \\
\text { Development Tools }\end{array}$ & $\begin{array}{l}\text { A good support of development } \\
\text { environment }\end{array}$ & $\begin{array}{l}\text { It still does not have a good development tool } \\
\text { and debugging support, which is convenient for } \\
\text { development. }\end{array}$ & $\begin{array}{l}\text { It has graphical configuration } \\
\text { tools, like Romfs. }\end{array}$ \\
\hline $\begin{array}{l}\text { The Price of Platform } \\
\text { Building }\end{array}$ & Almost ten thousand & -- & -- \\
\hline $\begin{array}{l}\text { The Price of } \\
\text { Commercial Copyright }\end{array}$ & About $\$ 3$ for a terminal & -- & -- \\
\hline
\end{tabular}

From Table 1, we could see that among these three embedded operating systems, WinCE has a better support of developing technology, which is beneficial to the development and rapid formation of embedded product. However, its price of developing platform and commercial copyright is up to ten thousand, which increases the developing cost of the system. While eCos and Linux need do more work when developing users, since they do not have a good development tool and debugging support that is not convenient for development.

\subsubsection{The Comparison of System Resources Occupation}

Also, we make a detailed statistics and contrast of the system resources occupation of these three embedded operating systems, as shown in Table 2-the list of system resources occupation:

Table2. The List of System Resources Occupation.

\begin{tabular}{llll}
\hline $\begin{array}{l}\text { System } \\
\text { Name }\end{array}$ & WinCE & Linux & eCos \\
\hline $\begin{array}{l}\text { Processor } \\
\text { and Basic } \\
\text { Frequency }\end{array}$ & Minimum: 2MB & $\begin{array}{l}\text { Minimum: } \\
\text { 2MB }\end{array}$ & $\begin{array}{l}\text { Dozens of KB } \\
\text { to hundreds of } \\
\text { KB }\end{array}$ \\
$\begin{array}{l}\text { ROM requ } \\
\text { irement }\end{array}$ & $\begin{array}{l}\text { Minimum: 200KB } \\
\text { Network: } 800 \mathrm{~KB}\end{array}$ & $\begin{array}{l}\text { More } \\
\text { than500K } \\
\text { (Exclude file }\end{array}$ & $\begin{array}{l}\text { Core code area } \\
\text { is less than }\end{array}$ \\
$\begin{array}{l}\text { RAM } \\
\text { requireme } \\
\text { nt }\end{array}$ & $\begin{array}{l}\text { GWES, She11and } \\
\text { Internet Exporer: } 3 \mathrm{MB}\end{array}$ & $\begin{array}{l}\text { protocol } \\
\text { stack) }\end{array}$ & $10 \mathrm{~K}$ \\
$\begin{array}{l}\text { Other } \\
\text { requireme } \\
\text { nt }\end{array}$ & More than 100MHz & $\begin{array}{l}\text { More than } \\
100 \mathrm{MHz}\end{array}$ & $\begin{array}{l}\text { No high } \\
\text { requirement. }\end{array}$ \\
\hline
\end{tabular}

Seen from Table 2, among WinCE, Linux, and eCos, the requirements of WinCE and Linux are relatively high, but there is no limitation of applicaions. Whilst eCos has a lower requirement, but it only could be applied by the objects who has a little amount of operation, since its limited applications.

\subsubsection{The Comparison of Real-Time Performance Parameter}

Moreover, we make a detailed statistics and contrast of real-time performance parameter of these three embedded operating systems, as shown in Table 3-the list of real-time performance parameter:

Table 3. The List of Real-time Performance Parameter

\begin{tabular}{llll}
\hline $\begin{array}{l}\text { System } \\
\text { Name }\end{array}$ & WinCE & Linux & eCos \\
\hline $\begin{array}{l}\text { The } \\
\text { Precision of } \\
\text { Timer }\end{array}$ & $1 \mathrm{~ms}$ & $\begin{array}{l}10 \mathrm{~ms}(\text { Could be } \\
\text { changed to } \\
1 \mathrm{~ms})\end{array}$ & Us degree \\
$\begin{array}{l}\text { Interrupt Lat } \\
\text { ency Time }\end{array}$ & Average: $9.5 \mathrm{us}$ & $\leq 10 \mathrm{~ms}(\approx 4 \mathrm{~ms})$ & $\approx 192 \mathrm{us}$ \\
$\begin{array}{l}\text { Context-swit } \\
\text { ching Time }\end{array}$ & $\approx 50 \mathrm{~ms}$ & $\approx 50 \mathrm{~ms}$ & $\approx 15.84 \mathrm{us}$ \\
$\begin{array}{l}\text { Thread-switc } \\
\text { hing Time }\end{array}$ & Average: $404 \mathrm{us}$ & $<10 \mathrm{~ms}$ & Us degree \\
$\begin{array}{l}\text { Testing } \\
\text { Environment }\end{array}$ & Xscale/400MHz & ARM/220MHz & MPC860/33 \\
\hline
\end{tabular}

According to Table 3, among WinCE, Linux, and eCos, eCos has the best real-time performance ${ }^{[5]}$; WinCE is next to it. However, the real-time performance of WinCE is better than the linux, which has the worst real-time performance. ${ }^{[6]}$

\subsubsection{The Comparison of System Functions}

Finally, we make a detailed statistics and contrast of functions of these three embedded operating systems, as 
shown in Table 4-the list of system functions:

Table 4. The List of System Functions

\begin{tabular}{|c|c|c|c|}
\hline System Functions & WinCE & Linux & eCos \\
\hline Power Management & Sleep/ wakeup mode & Support & Support \\
\hline Time Management & 1mstime precision & $1 \mathrm{~ms}$ time precision with low volume & $\mu$ s degree time precision \\
\hline Interrupt Management & Divided into IRS and IRT & Interrupt the context mechanism & Support \\
\hline Memory Management & $\begin{array}{l}\text { Three levels of management: physical } \\
\text { memory, virtual memory, and logic } \\
\text { memory. }\end{array}$ & $\begin{array}{l}\text { Providing address mapping and } \\
\text { paging supervisor }\end{array}$ & $\begin{array}{l}\text { Could configure the file system, } \\
\text { Ronfs that it supports. }\end{array}$ \\
\hline $\begin{array}{l}\text { Input/ Output } \\
\text { Management }\end{array}$ & Support & Support & Support \\
\hline Task Management & Max processors: 32000 & $\begin{array}{l}\text { Support preemptive, the priority of } \\
\text { scheduling process, supporting a } \\
\text { maximum of thousands processors, } \\
\text { the number of priority is } 140 \text {. }\end{array}$ & $\begin{array}{l}\text { A single process, multithread } \\
\text { system, the priority of } 32 \text { tasks, } \\
\text { supporting a maximum of } 32 \text { tasks. }\end{array}$ \\
\hline Task Communication & $\begin{array}{l}\text { critical region, mutex, semaphore, } \\
\text { event, interlocked functions and } \\
\text { message queue, pipe, socket, shared } \\
\text { memory, etc. }\end{array}$ & $\begin{array}{l}\text { Semaphore, signal, e-mail, message, } \\
\text { message queue pipe, socket, shared } \\
\text { memory, etc. }\end{array}$ & $\begin{array}{l}\text { Mutual exclusion, conditional } \\
\text { variable, signal, time stamp, e-mail. }\end{array}$ \\
\hline File Management & $\begin{array}{l}\text { Providing three types of file system: } \\
\text { RAM file system, ROM file system, } \\
\text { and installable file system. }\end{array}$ & $\begin{array}{l}\text { Support a variety of common file } \\
\text { systems, and virtual file systems. }\end{array}$ & $\begin{array}{l}\text { Could configure the file system, } \\
\text { Ronfs, which it supports. }\end{array}$ \\
\hline
\end{tabular}

From Table 4, among WinCE, Linux, and eCos, WinCE has the best capacity of system processing and file support, which could support several modes in power management. While the time management accuracy of eCos is the highest. Compared to WinCE and eCos, Linux is very common.

\section{Conclusion}

The developments of computer networks and wireless communication and energy crisis have made us attach importance to energy issues. Modern electrical automation system is required to have not only network access capabilities, but also more optimal power consumption. Therefore, embedded development technology of automation system is also made newer and higher requirements: (1) Embedded systems must support the network interconnection capabilities. Especially with the development of internet of things, embedded system is increasingly demanded to have network connectivity features, including wired and wireless network connectivity. (2) The embedded system must support friendly interface development because embedded products are used more and more widely, interface requirements also will be higher and higher. (3) The embedded system product must be produced rapidly and it must be conducive to market development. (4) The kernel of embedded system must be as concise as possible, its algorithms as optimized as possible, its power consumption and the cost of hardware and software as minimized as possible too. (5) The embedded system must have the intelligence error tolerance, because the scale of automated control systems will become increasingly large, and the probability of failure will be higher and higher. ${ }^{[7]}(6)$ The development of embedded system must comply with the principles of environmental technology aesthetics and laws, so that the embedded system development and innovation advance along the health, science, ecology road.

All in all, the embedded automation system equipment has more and more close relationship with human lives, and its development ideas and development technologies must also meet the needs of the times. ${ }^{[7]}$ At this point, we may take Sun Yat-sen's famous saying as a warning: "The world trend is mighty. The people advancing with tide are prosperous, while the people advancing against tide will perish."

\section{Brief Introduction to the Author}

Yue Xiangyu (1992- ), who is a male, Han nationality, was born in Weifang, Shandong, with BA, Nanjing University, mainly engaged in electrical information and automation, aesthetics and other aspects of learning and research, specializing in modern industrial embedded control systems, networked control systems, intelligent control. He presided over one national college student science and technology innovation project, taking part in the research on one "Eleventh Five-Year Plan" education and science key project of the Education Ministry, and one soft science research project of Shandong Province. He has 12 science and technology papers published in Chinese and oversea academic journals. He has won the 1st scholarship of China, the 1st scholarship of people, the 1st and the 2nd prizes of China Education Robotics Competition, the 1st prize of China Mathematical Modeling Contest, the top award of scientific research achievement of Nanjing University, two China science and technology patents and the honorary title, "three-good-student" of Jiangsu Province. In addition, as a representative of Nanjing University, he 
went to the National University of Singapore to participate in an academic exchange program. Address: School of Management and Engineering, Xianlin Campus of Nanjing University, 163, Xianlin Avenue, Qixia District, Nanjing, Jiangsu Province, PR China; Zip: 210008.

\section{References}

[1] Zhang Ying, Li Peng, Chen Lifeng, Gong Yongguang, etc. The Survey of Embedded System Development[A]. Electronic Technology [J], 2008, 6 (5): 74-77.

[2] Guo Qiyi, Zou Jie, Zhao Yanhua, etc. Industrial embedded operating system overview[A]. Railway Locomotive [J], 2003, 1 (28): 4-8.
[3] Wei Junhua. The embedded real-time operating system overview[A]. Technology Square [J], 2011, 1 (30): 254-256.

[4] Li Qingcheng, Tang Dekai. The real-time comparison and evaluation of embedded operating system[A]. Microcontrollers \& Embedded System Application [J], 2007, 6: $18-20$.

[5] Zhu Xiangbin, Tu Shiliang. Linux real-time performance test [A]. Microelectronics \& Computer [J], 2004, 12 (20): 85-88.

[6] Yu Bing, Li Zhongwen. The real-time analysis of Linux operating system[A]. Computer Technology and Development [J], 2007, 9: 41-45.

[7] Huang Xiongfeng, Yang Mingyue, Ma Jie. The Summary of Automation System Embedded Development Research Technology[A]. PLC \& FA [J], 2011, (10): 35-38. 